\title{
O NOVO AMBIENTE DE NEGÓCIOS EM UM “MUNDO PLANO”: A INFLUÊNCIA ESTRATÉGICA DAS TECNOLOGIAS DE INFORMAÇÃO E COMUNICAÇÃO
}

Taiana Melo da Silva (UFF)

taianamelo@hotmail.com

Carlos José Guimarães Cova (UFF)
cjcova@terra.com

Eduardo Picanço Cruz (UFF)

epicanco@vm.uff.br

\section{Carlos Navarro Fontanillas (UFRJ) navarro@pep.ufri.br}

\section{RESUMO}

0 presente artigo se propõe a evidenciar alguns aspectos relativos à importância da Tecnologia de Informação e Comunicação para o bom desempenho na ambiente de negócios. A inspiração para este trabalho surgiu a partir da leitura do livro de Thomas Friedman, O Mundo é Plano, sugerido durante o curso de Administração da Produção na UFF como leitura complementar. Na obra de Friedman é possível aquilatar a importância da Tecnologia de Informação para a promoção de ganhos de eficiência nas operações das empresas, corroborando as idéias de Michael Porter no início dos anos 80.0 autor afirma que a transformação tecnológica que é capaz de afetar a vantagem competitiva e a estrutura industrial constitui-se num dos principais fatores de mudança nas regras da concorrência de um determinado mercado. Nesse sentido, a tecnologia extrapola o produto em si mesmo e impacta toda a cadeia de valor das empresas. É esse o caso da Tecnologia de Informação e Comunicações no atual ambiente de negócios, na medida em que elimina as distâncias e aumenta o nível de integração dos agentes econômicos. Ao eliminar as distâncias, a TIC eliminaria também os obstáculos de ligação do Planeta, como se o transformasse numa grande planície, daí a expressão "Mundo Plano" empregada por Friedman.

Palavras-chave: Mundo plano. Tecnologia da informação. Internet. Comunicação.

\section{ABSTRACT}

This article aims to highlight some aspects of the importance of Information and Communication Technologies for the good performance in the business environment. The inspiration for this work came from reading the book by Thomas Friedman, The World is Plan, suggested during the course of Administration of Production in UFF as supplementary reading. In Friedman's book, is possible to assess the importance of Information Technology Services for the promotion of efficiency in the operations of enterprises, corroborating the Michael Porter's ideas in the early 80. The author afirms that the technological transformation that is capable of affecting the competitive advantage and industry structure is one of the main factors of change in the rules of competition in a particular market. In this sense, technology beyond the product itself and impacts the entire value chain of businesses. That is the case of the Information and Communications Technology in today's business environment, and it eliminates the distance and increases the level of integration of economic agents. By eliminating distances, the ICT also eliminates the obstacles to linking the world, as if transforming in a vast plan land, hence the term "World Plan" employed by Friedman.

Key-Words: World is plan. Information technology. Internet. Communication. 


\section{INTRODUÇÃO}

A Tecnologia da Informação (TI) pode ser considerada como sendo o conjunto de recursos não humanos empregados na coleta, armazenamento, processamento e distribuição da informação. A convergência entre os recursos de informática e os de telecomunicações deu origem ao termo Tecnologia da Informação e Comunicação (TIC), que integra em sua infraestrutura, o hardware, o software e as tecnologias de comunicação.

De acordo com Rezende et alii (2006), o hardware designa os dispositivos físicos de um computador, usados para entrar, processar armazenar e sair com dados e informação. Por sua vez o software é o conjunto de comandos, instruções ou ordens elaboradas pelo cliente e/ou usuário para o computador cumprir, visando resolver problemas e desenvolver atividades ou tarefas específicas. As tecnologias de comunicação englobam um conjunto de métodos, técnicas e ferramentas que possibilitam a criação de sistemas de comunicação.

A evolução de tais tecnologias possibilitou a comunicação entre os computadores e, a partir dessa interação, tais máquinas deixaram de simplesmente automatizar tarefas e passaram a lidar com a informação numa escala jamais imaginada, compilando, processando, organizando e comparando dados, de sorte a permitir uma redução da incerteza e o conseqüente fortalecimento da capacidade de tomada de decisão.

\section{DADOS, INFORMAÇÕES E CONHECIMENTO}

Os dados são descrições elementares de coisas, eventos, atividades e transações que são registrados, classificados e armazenados, mas não organizados, ou seja, tomados isoladamente, não transmitem qualquer significado específico.

Por sua vez, a informação refere-se aos dados organizados de modo a terem significado e valor para quem usa a informação, ou seja, para o receptor. A informação pressupõe uma estruturação dos dados, de tal forma a dotá-los de significado. Já o conhecimento consiste em dados e/ou informações organizadas e processadas para transmitir entendimento, experiência, aprendizagem acumulada e prática. Ele possui um caráter fortemente idiossincrático, e se manifesta de forma assimétrica, instintiva e não linear. Sua manifestação é indispensável para a produção de inovações tecnológicas e para a manutenção da vantagem competitiva por via da gestão do capital intelectual das empresas. De acordo com Nonaka et alii (1997), o conhecimento poderia ser classificado em dois grandes grupos: o conhecimento tácito, que é pessoal, específico do contexto e difícil de formalizar e comunicar, pois está na mente do indivíduo; e o conhecimento explícito, que é aquele que é transferido em linguagem formal e sistemática, e está por exemplo nos livros e manuais.

Conforme lembram Abreu et alii (2006), as empresas que detiverem, organizarem, dominarem e valorizarem mais a informação e o conhecimento do meio ambiente (interno e externo) em que estiverem envolvidas terão mais condições de competitividade nos negócios.

Ainda de acordo com esses autores, os dados, as informações e os conhecimentos permitem que os gestores tomem as decisões, que são atos mentais. As decisões permitem que os gestores possam executar as ações, que são atos físicos. Todas essas atividades geram novos dados, informações e conhecimentos num ciclo retroalimentado, a fim de contribuir com a inteligência empresarial das organizações.

Para tanto, o uso da tecnologia nas empresas tornou-se imprescindível, ou seja, sem investimentos na informatização da organização operar com eficiência passou a ser 
impossível. Devido a essa revolução no ambiente de gestão, os Sistemas de Informação (SI) passaram a ocupar dentro da empresa um papel cada vez mais relevante.

\section{OS SISTEMAS DE INFORMAÇÃO NO AMBIENTE EMPRESARIAL}

Laudon e Laudon (1997) definem um sistema de informação como sendo um conjunto de componentes inter-relacionados trabalhando juntos para coletar, recuperar, processar, armazenar e distribuir informação com a finalidade de facilitar o planejamento, o controle, a coordenação, a análise e o processo decisório em empresas e outras organizações.

Turban et alii (2007) assumem que a finalidade dos sistemas de informação é obter as informações certas para as pessoas certas, no momento certo, na quantidade certa e no formato certo.Em uma empresa são usados muitos tipos de sistemas de informação e os mesmos fornecem a organização suporte, tanto dentro de uma única organização quanto entre organizações.

Nesse sentido, os autores definem um ciclo de três atividades básicas realizado por qualquer tipo de sistema de informação: a entrada, o processamento e a saída. Onde, a entrada (ou input) envolve a captação ou coleta de fontes de dados brutos de dentro da organização ou de seu ambiente externo. 0 processamento envolve a conversão dessa entrada bruta em uma forma mais útil e apropriada. A saída (ou output) envolve a transferência da informação processada às pessoas ou atividades que a usarão.

Os sistemas de informação também armazenam informação sob várias formas, até que ela seja necessária para o processamento ou saída. A realimentação (ou feedback) é a saída que retorna aos membros adequados da organização para ajudá-los a refinar ou corrigir os dados de entrada.

Um sistema de informação eficiente pode ter um grande impacto na estratégia corporativa e no sucesso da empresa. Esse impacto pode beneficiar a empresa, os clientes e/ou usuários e qualquer indivíduo ou grupo que interagir com os sistemas de informação.

São muitos os benefícios que as empresas podem obter com o uso de sistemas de informação. Encontramos em Abreu et alii (2006) um elenco dos benefícios que podem ser auferidos pelas organizações com o seu uso:

. suporte à tomada de decisão profícua;

. valor agregado ao produto (bens e serviços);

. melhor serviço e vantagens competitivas;

. produtos de melhor qualidade;

. oportunidade de negócios e aumento da rentabilidade;

. mais segurança nas informações, menos erros, mais precisão;

. aperfeiçoamento nos sistemas, eficiência, eficácia, efetividade, produtividade;

. carga de trabalho reduzida

. redução de desperdícios; 
. controle das operações etc.

Uma organização moderna processa muitos recursos de informação, termo geral que, de acordo com Turban et alii (2007) inclui todo o hardware, o software (sistemas de informações e aplicações), os dados e redes de uma empresa. É razoável admitir que todos esses recursos são de enorme valor estratégico para a empresa, além de custar caro para empresa a sua manutenção e operação. Tais recursos, portanto, exigem muito da organização no que se refere a um gerenciamento cada vez mais eficiente. As dificuldades encontradas pelas empresas são explicadas pelo fato de que, quando estas começaram a usar computadores, no início da década dos anos 1950, o departamento de sistemas de informação (DSI) possuía o único recurso de computação da organização, o mainframe. Nessa época, os usuários finais não interagiam diretamente como o mainframe. Ao passo que, atualmente, as empresas não conseguem sequer funcionar sem todo esse aparato tecnológico, de sorte que os computadores estão em toda parte, integrando todos os processo e sendo usado pela maioria dos colaboradores.

Mas, para que exista tal integração e comunicação entre computadores, bem como a transmissão de dados entre os mesmos a existência de uma rede de computação é fundamental. Somente através das redes, o computador ganha poder e transformam-se em uma ferramenta incrivelmente eficaz de pesquisa, comunicação e colaboração, aumentando enormemente a produtividade e a vantagem competitiva da empresa.

Os tipos de redes variam de pequenas a mundiais e, incluem as redes locais (LANs), redes remotas (WANs) e a Internet. Uma rede local (LAN - Local Area Network) conecta dois ou mais dispositivos em uma região geográfica limitada, normalmente dentro do mesmo prédio, de modo que cada dispositivo na rede tem o potencial de se comunicar com os outros dispositivos. Uma rede remota (WAN - Wide Area Network) é uma rede que cobre grandes áreas geográficas, geralmente são oferecidas por operadoras comuns, como companhias telefônicas e redes internacionais de provedores de serviços de comunicação global.

As redes apoiam novos meios de fazer negócios, do marketing e gerenciamento da cadeia de suprimentos até o serviço ao cliente e o gerenciamento de recursos humanos.

Permitem às empresas maior flexibilidade para se adaptarem as condições de negócios que mudam rapidamente. Possibilitam o compartilhamento de hardware, de aplicações de computador e de dados dentro da organização e entre organizações.

Em especial a Internet e suas correspondentes organizacionais privadas, as intranets, exercem um enorme impacto sobre nossa vida tanto profissional quanto pessoal. Na verdade, para todas as organizações, ter uma estratégia de Internet não é mais apenas uma fonte de vantagem competitiva - é vital para a sobrevivência

\section{A INTERNET}

Também chamada de rede mundial de computadores, pode ser definida como uma rede de redes e é reconhecidamente uma necessidade na condução dos negócios modernos.

Surgiu de um projeto experimental da Advanced Research Project Agency (ARPA) do Departamento de Defesa dos Estados Unidos. O projeto começou em 1969 com o nome de ARPAnet. Sua finalidade era testar a viabilidade de uma WAN através da qual pesquisadores, educadores e órgãos militares e governamentais pudessem compartilhar dados, trocar 
mensagens e transferir arquivos.

Durante a década de 70, com a revisão das limitações dos programas utilizados nos computadores em rede, o e-mail (eletronicmail) tornou-se o primeiro uso da Internet. As aplicações comerciais só começariam a acontecer nos anos $80 \mathrm{com}$ os primeiros provedores de serviço da Internet (ISP - International Service Providers) possibilitando ao usuário comum a conexão com a Rede Mundial de Computadores, de dentro da sua casa.

Laudon e Laudon (2007) destacam a Internet como sendo a mais usada das redes, conectando organizações empresariais, governamentais, científicas e educacionais, assim como indivíduos, através do globo.

0 que distingue a Internet de outros meios de telecomunicação é que ela faz uso de uma linguagem ou protocolo específico, chamado TCP/IP (Transmission Control Protocol /Internet Protocol), que lê a informação transmitida e a envia para o destino estabelecido pelo usuário.

Parte do crescimento fenomenal da Internet pode ser atribuída a uma estrutura conhecida como WWW (World Wide Web). 0 conceito de World Wide Web - um sistema para criação, organização e interligação de documentos, possibilitando a fácil navegação entre eles - foi elaborado pelo especialista da computação britânico Tim Berners-Lee, que criou o primeiro site da web em 1991, na tentativa de fomentar uma rede de computadores que possibilitasse aos cientistas compartilhar suas pesquisas com facilidade (Friedman, 2006).

\section{World Wide Web}

A Internet funciona como um mecanismo de transporte, enquanto a World Wide Web (a Web, WWW ou W3) é uma aplicação que usa essas funções de transporte (Turban et alii, 2007).

É definida como um sistema de padrões universalmente aceitos para armazenar, recuperar, formatar e exibir informações por meio de uma arquitetura cliente/servidor.

Manipula todos os tipos de informação digital, incluindo textos, hipermídia, gráficos e sons.

Aliada ao baixo custo e a facilidade de uso, toda essa capacidade faz da Web uma plataforma flexível e barata para criação de novos tipos de sistemas de informação.

0 acesso a Web se dá através de aplicações de software denominadas navegadores, estes possuem uma interface gráfica que possibilita ao usuário utilizar o mouse para navegar pela Web. Os navegadores Web se tornaram um meio de acesso universal porque apresentam a mesma interface em qualquer sistema operacional sobre o qual são executados.

- Web 1.0 - Anos 90: Tal fase caracterizou a implantação e a popularização da rede em si. Funcionava como uma grande biblioteca digital. Foi a primeira geração de Internet comercial. Armazenava grande quantidade de informação, mas seu conteúdo era pouco interativo. 0 usuário ficava no papel de mero espectador da ação que se passava na página que ele visitava. Não era possível a alteração de seu conteúdo.

- Web 2.0 - Hoje: Possibilita a construção coletiva do conhecimento. Permite que os usuários sejam mais do que meros espectadores, o ambiente on-line se torna mais dinâmico e os usuários colaboram para a geração e organização de conteúdo. Centrada nos mecanismos de busca como Google e nos sites de colaboração do internauta, como Wikipédia, YouTube e os sites de relacionamento social, como o Orkut. 
- Web $3.0^{1}$ - A Web Semântica: Propõe-se a ser, num período de cinco a dez anos, a terceira geração da Internet, organizando e possibilitando o uso de maneira mais inteligente de todo o conhecimento hoje disponível. Projeta estruturar todo o conteúdo disponível na rede mundial de computadores dentro dos conceitos de "compreensão das máquinas" e "semântica das redes". 0 foco estará nas estruturas dos sites e menos nos usuários e a convergência de várias tecnologias resultará em um grande salto de sinergia. 0 objetivo é desenvolver tecnologias e linguagens que tornem a informação legível para as máquinas, o que permitirá aos computadores e humanos trabalharem em cooperação.

\section{A INFLUÊNCIA DA TIC NO AMBIENTE CORPORATIVO}

No contexto atual, de acordo com Oliveira (2006), a existência das tecnologias da informação e da comunicação representa um suporte indispensável quando consideramos as estratégias de desenvolvimento dos negócios. Compreendê-las de maneira extensiva é fator de sobrevivência. E, manter as ações de gestão devidamente atreladas à modernidade tecnológica representa a garantia de decisões rápidas, eficientes e objetivas. Os sistemas de informação e de comunicação hoje permeiam e mesmo viabilizam virtualmente todas as atividades humanas, e não mais podemos conceber a sociedade sem sua acentuada imbricação com as tecnologias de informação que nela surgem e que a modificam.

A cada dia torna-se mais perceptível a importância da Tecnologia da Informação na transformação das empresas, afinal sua atribuição principal é viabilizar projetos e serviços que agreguem valor ao negócio da empresa.

É fundamental perceber que as atividades empresariais não podem ser organizadas simplesmente com o uso de computadores e recursos de software, por mais tecnologia que detenham. 0 componente fundamental é o recurso humano, pois, sem ele, todo o aparato tecnológico não teria funcionalidade nem utilidade.

As empresas foram forçadas a se estrututrarem de maneira diferenciada, as alianças, as parcerias, a exploração de novos mercados e inúmeras outras mudanças advindas da evolução nas tecnologias de informação, resultaram sobretudo da facilidade em se obter e trocar informações.

É consensual a importância da informação para a sobrevivência de uma empresa, em particular no que se refere a tomada de decisões. Para tanto, Rezende (2002) lembra que, como as organizações estão atualmente enfrentando um mercado competitivo, globalizante e turbulento, elas necessitam de informações oportunas e conhecimentos personalizados para, efetivamente auxiliar sua gestão de forma inteligente.

Algumas das finalidades do uso de sistemas de informação pelas empresas é a busca de soluções para uma variedade de problemas organizacionais, além da busca pela maneira correta para reagir a uma mudança no ambiente. Os sistemas de informação devem, ainda, apresentar respostas e atender aos interesses da gestão, bem como auxiliar no processo decisório.

Para Abreu et alii (2006) o trabalho de uma empresa depende de uma forma crescente do que os sistemas de informação são capazes de fazer. 0 aumento da participação no mercado, a

1 Os conceitos de Web 1.0, 2.0 e 3.0 foram extraídos de http://pt.wikipedia.org/wiki/web_3.0. e http://pt.wikipedia.org/wiki/Web_sem\%C3\%A2ntica em 03/06/2008 às 21h54min. 
redução de custos de produção, o desenvolvimento de novos produtos e/ou o orçamento da produtividade do empregado depende mais e mais dos tipos e qualidade dos sistemas de informação na empresa.

Tais objetivos, planos e políticas formam as estratégias de uma empresa para competir e esse conjunto é denominado por Porter (1985) como sendo a estratégia competitiva. E é por meio dessa estratégia competitiva que a empresa busca uma vantagem competitiva em determinado setor.

Turba net alii (2007) relacionam o modelo das cinco forças competitivas de Porter com o advento da Tecnologia de Informação e Comunicação, demonstrando o quanto a TIC pode tornar a empresa mais competitiva e como a Internet as influencia.

a) A ameaça da entrada de novos concorrentes: a Internet aumenta a ameaça de novos entrantes na medida em que reduz drasticamente as barreiras tradicionais à entrada, como a necessidade de uma força de vendas ou um ponto físico para oferecer produtos e serviços.

Além do alcance geográfico de Internet que permite que concorrentes distantes concorram mais diretamente com uma empresa existente.

b) 0 poder de barganha dos fornecedores: por um lado, os compradores podem encontrar fornecedores alternativos e comparar preços mais facilmente, o que reduz o poder de barganha do fornecedor. Por outro lado, a Internet integra as cadeias de suprimento e os fornecedores participantes dessas cadeias prosperam por meio da união com clientes.

c) 0 poder de barganha dos clientes (compradores): o acesso às informações sobre produtos e

fornecedores tornou-se mais significativo com a Web. 0 poder de barganha dos clientes é aumentado devido também à facilidade da troca de fornecedores, pois possibilita menos custos de mudança.

d) A ameaça de produtos e serviços substitutos: os setores em que informações digitalizadas possam substituir produtos físicos precisam ver a Internet como uma ameaça, pois a rede pode transmitir essas informações de maneira eficiente e barata.

e) A rivalidade entre empresas existentes no setor: diferenças cada vez menores entre concorrentes é resultado da visibilidade das aplicações de Internet na Web que torna mais difícil de manter em segredo os sistemas proprietários. Enfim, de inúmeras formas os sistemas baseados em Internet estão mudando a natureza da concorrência e mesmo a estrutura dos mais variados setores.

Faria apud Oliveira (2006) vai ao encontro dessa idéia de consolidar o papel estratégico da área de TI e sua contribuição nas organizações, quando afirma que as atividades que envolvem soluções suportadas por TI tornam-se cada vez mais imprescindíveis nos diversos segmentos de mercado. E influenciam positivamente o sucesso e a rentabilidade dos negócios. Para esse autor, de forma geral, as principais expectativas dos executivos de negócios em relação às iniciativas de TI são as seguintes:

. aumento da produtividade e da eficácia operacional;

. redução de riscos e de custos nas operações; 
. qualificação, otimização e integração dos processos de negócio;

- garantia e disponibilização de informações consistentes, atualizadas e que permitam suportar as decisões.

Ainda de acordo com Turba net alii (2007) é necessário ter em mente que a tecnologia desempenhará um papel cada vez mais vital em cada função e departamento das organizações comerciais modernas. Ele apresenta as conexões entre a TIC e cada um dos setores típicos de uma organização:

a) Setor de contabilidade: os sistemas de processamento de transações - que agora são baseados na web - capturam, organizam, analisam e disseminam dados e informações por toda a organização, normalmente por meio de intranets corporativas. A Internet aumentou significativamente o número de transações (especialmente globais) em que se envolvem as empresas modernas. Tais transações geram dados que a contabilidade precisa registrar e controlar e, em relação as que acontecem com clientes e fornecedores hoje são feitas online, através de extranets. Além disso, os sistemas de informação de contabilidade precisam compartilhar informações com sistemas de informação de outras partes da organização. Por exemplo, informações transacionais de um SI de vendas ou marketing agora são também uma entrada para o sistema de contabilidade.

b) Setor de finanças: o mundo financeiro moderno depende da velocidade, do volume e da precisão do fluxo de informações e os sistemas de informação, bem como as redes tornam tudo isso possível. Os departamentos de finanças usam sistemas de informação para monitorar mercados financeiros mundiais e para fornecer análises quantitativas, além desses sistemas fornecerem apoio à tomada de decisões financeiras. Analogamente ao SI de contabilidade, os sistemas de informação de grande porte integram intimamente as finanças com todas as outras áreas funcionais dentro da empresa.

c)Setor de marketing: para executar suas funções o marketing usa bancos de dados de clientes, sistemas de apoio à decisão, automação de vendas, data warehouses e softwares de inteligência empresarial. A Internet criou um canal global inteiramente novo para o marketing através do business-to-business (B2B, entre empresas) e do business-to-consumer (B2C, entre empresa e consumidor). E ainda aumentou consideravelmente a quantidade de informação disponível aos consumidores, que, agora, podem comparar preços de modo rápido e abrangente. Como resultado, os vendedores se tornaram mais bem informados e sofisticados e, os gerentes de marketing, por sua vez, precisam se dedicar mais para conquistar e manter os clientes. Devido a isso, para ter um bom resultado, são usados softwares de gestão do relacionamento com o cliente. A Internet permite um contato mais próximo entre o consumidor e o fornecedor.

d) Setor de produção/operações: atualmente as organizações competem em termos de preço, qualidade, tempo (velocidade) e serviço ao cliente - gerando preocupações para o gerente de produção e operações. Cada um dos processos nas operações de uma empresa que agrega valor a um produto ou serviço pode ser aprimorado pelo uso de sistemas de informação baseados na web. Além disso, os sistemas de informação fornecem apoio a essas funções permitindo, por exemplo, que a função de produção e operações vincule a organização com outras organizações na cadeia de suprimentos da empresa.

e) Setor de recursos humanos: é valioso o apoio que os sistemas de informação fornecem para o gerenciamento de recursos humanos. A manutenção de registros, por exemplo, tornou-se 
significativamente melhor em termos de velocidade, conveniência e precisão. Além disso, disseminar informações de RH através da empresa via intranets permite que os empregados recebam informações constantes e manipulem, eles próprios, muitos de seus interesses pessoais, como, por exemplo, configurar os próprios benefícios, sem a ajuda do pessoal de RH. Isso sem falar que a Internet disponibiliza uma enorme quantidade de informações para quem procura emprego, aumentando a fluidez do mercado de trabalho. Finalmente, muitas carreiras exigem experiência no uso de sistemas de informação. Os profissionais de RH precisam ter conhecimento desses sistemas e habilidades para lidar com contratação, treinamento e retenção dentro de uma organização.

Interligando tais sistemas dentro da organização temos o Sistema de Informação Gerencial (SIG), que consiste em um tipo de SI de área funcional, mas tem a responsabilidade de fornecer as informações de que cada uma das áreas funcionais necessita para tomar decisões. Isto é, apóia diretamente qualquer pessoa dentro da organização, englobando todos os componentes da organização e todos os seus níveis de decisão. 0 SIG tem como características básicas: dados sintéticos, comparativos, com pouco volume, com ágil tempo de resposta e visualização dos dados. 0 objetivo geral do departamento de SIG é resolver os problemas empresariais dos usuários por meio da tecnologia de informação. Ou seja, promovem uma interface entre usuários empresariais de um lado e os programadores, essenciais ao desenvolvimento e manutenção dos SIs, de outro.

Para Carlos Simonsen ${ }^{2}$ o advento das tecnologias ditas de informação, sobretudo a partir da década de 1990, mudou e continuará mudando os paradigmas de funcionamento das organizações, sejam elas públicas ou privadas, com ou sem fins lucrativos.

Não obstante, a tomada de decisão dependerá cada vez mais de uma conscientização das mudanças estratégicas engendradas pelas novas tecnologias. A identificação de novas ameaças e caminhos advirá da percepção do papel das tecnologias de informação tanto no funcionamento dos mercados quanto na reestruturação da produção e da distribuição de bens e serviços.

De acordo com Oliveira (2006), posicionar-se criticamente diante de cenários marcados pelo caráter competitivo e decidir-se por perseguir determinadas soluções, em tempos cada vez mais críticos, traduz o perfil necessário para atuar em atividades nas quais a modernidade é componente decisivo para o sucesso.

Para Friedman (2007) assistiremos ao fim do antigo paradigma de uma única multinacional americana ou européia cuidando, a partir de seus próprios recursos, de todos os elementos do ciclo de desenvolvimento de um dado produto. Afinal, um número crescente de empresas americanas e européias está terceirizando tarefas significativas de pesquisa e desenvolvimento para Índia, a Rússia e a China.

Afinal, conforme descrito por ele, as empresas japonesas podem contratar três engenheiros de software chineses pelo preço de um no Japão - e ainda sobra troco para contratar uma sala cheia de atendentes de call center (salário inicial de 90 dólares mensais).

Não admira que cerca de 2.800 empresas japonesas tenham instalado aqui suas operações ou constituído parcerias com chineses.

2 Carlos Ivan Simonsem Leal, presidente da Fundação Getúlio Vargas. Vide prefácio livro: Tecnologia da Informação e da Comunicação: Desafios e propostas estratégicas para o desenvolvimento dos negócios (2006). 
Friedman comenta a frase de Xia Deren, prefeito de Dalian, China "os chineses primeiro foram os empregados, a serviço dos grandes fabricantes estrangeiros; ao fim de alguns anos, depois que aprendemos todos os processos e etapas, começamos nossos próprios negócios. 0 software seguirá o mesmo caminho. (...) Primeiro, nossos jovem vão trabalhar para os estrangeiros, depois vamos fundar nossas próprias empresas. É como construir um prédio. Hoje, vocês, americanos, são os engenheiros, os arquitetos, e os países em desenvolvimento são pedreiros. Mas um dia, espero, seremos nós os arquitetos".

A dispersão, afirma Friedman, explica o exemplo ora citado, afinal tudo isso se tornou possível na medida em que foi viável para as empresas e indivíduos dispersarem o trabalho e transferi-lo para qualquer lugar do mundo.

Outrossim, o autor vai ao encontro da idéia da influência da TIC, pois, através dela é possível a criação de sistemas de informação que possibilitem que todos os departamentos internos da empresa - vendas, marketing, produção, cobrança, estoque - tornem-se interoperáveis, independentemente dos equipamentos ou programas utilizados por cada um. E afirma que, para o mundo se tornar plano de verdade, todos os sistemas de cada empresa teriam de poder comunicar-se sem restrições com todos os sistemas de todas as demais empresas.

Dessa maneira, quando certa empresa fechasse uma venda, um determinado item seria remetido automaticamente do depósito do seu fornecedor, ao mesmo tempo em que outro seria automaticamente fabricado pelo fornecedor do seu fornecedor, enquanto 0 departamento de cobrança emitiria a fatura correspondente à operação - e a comunicação entre os diferentes sistemas e aplicativos de cada uma dessas três organizações diferentes teria de ocorrer sem entraves, de modo que o trabalho pudesse fluir entre eles.

Para Friedman, assim aconteceu quando os aplicativos de todo o Mundo começaram a conversar uns com os outros, de forma que o trabalho passou não só a fluir como nunca antes, mas também passou a poder ser desmembrado, desagregado e espalhado pelos quatro cantos do mundo de uma maneira inédita.

Comenta ainda esse autor: "Não só passamos a nos comunicar entre nós numa escala sem precedentes, como agora podemos colaborar, criar coalizões, projetos e produtos juntos como nunca antes", diz Joel Cawley, estrategista da IBM.

0 autor, apoiado em diferentes exemplos, defende que as empresas inteligentes são as que estão estimulando, em vez de combater, o crescimento vertiginoso de enormes comunidades online - muitas das quais surgiram na periferia da web, atraindo dezenas de milhões de participantes da noite para o dia. Até mesmo concorrentes ferrenhos estão colaborando em iniciativas científicas revolucionárias que aceleram a descoberta em seus campos de atuação.

Para essa nova tendência de pensamento, o fato é que, com um número cada vez maior de empresas percebendo os benefícios da colaboração em massa, esse novo modo de organização acabará por substituir as estruturas empresariais tradicionais como o motor primário de criação de riqueza na economia.

Até os clientes adquirem outra postura na chamada era da comunicação em massa. De acordo com eles, os clientes se tornam "prosumers" (neologia para se referir a consumidores que também são produtores), contribuindo na criação de bens e serviços em vez de simplesmente consumirem o produto final.

Com isso, muitas empresas estão se beneficiando desse novo paradigma nos negócios, afinal 
essas organizações e os líderes adotaram a colaboração e a auto-organização como novas e poderosas alavancas para reduzir custos, inovar mais rápido, criar em parceria com clientes e sócios e, em geral, fazer o que for necessário para entrar no ambiente empresarial do século XXI.

Tapscott e Willians, através de pesquisas da New Paradigm ${ }^{3}$, buscam entender como a web muda a empresa e como as companhias inovam, criam relacionamentos, colocam seus produtos no mercado e concorrem. E afirmam que empresas que se envolvem com essas comunidades surgidas graças à web já estão descobrindo os verdadeiros dividendos da competência e da genialidade coletiva.

As oportunidades de longo alcance para todas as empresas e pessoas que se conectaram é conseqüência de estarmos entrando em uma nova era, na qual as pessoas participam da economia como nunca antes. Essa nova participação atingiu um ápice no qual novas formas de colaboração em massa estão mudando a maneira como bens e serviços são inventados, produzidos, comercializados e distribuídos globalmente.

Tudo isso é possibilitado pelo fato de o acesso crescente à tecnologia da informação colocar na ponta dos dedos de todos as ferramentas necessárias para colaborar, criar valor e competir. 0 que libera as pessoas para participarem da inovação e da criação da riqueza em cada setor da economia. Milhões de pessoas já unem forças em colaborações auto-organizadas que produzem novos bens e serviços dinâmicos que rivalizam com os das maiores e mais bem-financiadas empresas do mundo.

Os autores citados denomina esse novo modelo de inovação e criação de valor de peer production ou peering - uma descrição do que acontece quando grupos de pessoas e empresas colaboram de forma aberta para impulsionar a inovação e o crescimento em seus ramos.

Chame-as de "armas da colaboração em massa", enfatizam os autores. Essas novas infraestruturas colaborativas de baixo custo - desde a telefonia grátis via internet até softwares de código aberto ou plataformas globais de terceirização - permitem que milhares de indivíduos e pequenos produtores criem conjuntamente produtos, acessem mercados e encantem os clientes de uma maneira que apenas as grandes empresas podiam fazer no passado, isso está fazendo surgir novas capacidades colaborativas e modelos de negócios que darão poder às empresas bem preparadas e destruirão aquelas que não forem capazes de se adaptar.

Para eles, essas mudanças, entre outras, estão abrindo caminho em direção a um novo mundo no qual conhecimento, poder e capacidade produtiva estarão mais dispersos do que em qualquer outro período da nossa história - um mundo no qual a criação de valor será rápida, fluida e persistentemente perturbadora.

Para as empresas de qualquer ramo já estabelecidas no mercado, essa nova cornucópia de participação e colaboração é ao mesmo tempo estimulante e alarmante. As empresas passaram as últimas três décadas remodelando as suas operações para concorrerem em uma economia hipercompetitiva - eliminado custos de seus negócios a cada oportunidade, tentando se tornar mais "agradável ao cliente", montando redes de produção globais e espalhando as suas organizações fisicamente constituídas de P\&D pelo mundo.

\footnotetext{
3 Programas de pesquisa realizados para entender como a nova web muda a empresa. Tais estudos são patrocinados por empresas. Os autores do livro já participaram de algumas dessas pesquisas.
} 
O livro de Friedman traz exemplos onde é possível observar que muitas empresas, antes pautadas em antigas estratégias de gestão, estão se beneficiando desse novo paradigma que se apresenta para o mundo dos negócios. E um desses casos que, além de interessante ilustra bem a tese por eles defendida é o da IBM, apresentado a seguir:

\section{A IBM E A EXPERIÊNCIA COM O CÓDIGO ABERTO}

Linus Torvalds ${ }^{4}$ criou o Linux em uma época que ninguém - a não ser os defensores mais aguerridos do código aberto - acreditava que o software de código aberto seria algo mais do que uma breve experiência de um hacker. Entretanto, em poucos anos o Linux criou um ecossistema de vários bilhões de dólares e desestabilizou a balança de poder da indústria de software.

As empresas que antigamente rivalizavam para controlar o lucrativo mercado de sistemas operacionais para computadores com as suas soluções de propriedade exclusiva agora estão repentinamente enfrentando a competição séria de uma alternativa grátis criada por uma rede livre de programadores, cujo objetivo nem é obter lucro.

Empresas inteligentes estão tendo de compreender que o código aberto é uma força a ser enfrentada e, que as mesmas devem aprender a co-existir e lucrar com a chegada de um novo modo de produção de software. E a IBM ilustra, de modo surpreendente essa transformação, afinal a Big Blue - empresa que se tornou enorme construindo e vendendo tudo o que fosse de propriedade exclusiva - era uma candidata improvável a campeã de peering e líder do mundo aberto.

A empresa, durante décadas criou softwares que só funcionavam nos computadores IBM, mas em uma surpreendente inversão de estratégia (e de sorte), a IBM adotou o código aberto como cerne dos seus negócios de uma forma que poucas organizações do seu porte e maturidade ousaram.

Por estar atento, em algumas áreas, às dificuldades em destronar concorrentes como a Microsoft, a IBM começou a investigar os softwares de código aberto e acabou doando um grande volume de códigos de softwares de propriedade exclusiva e criando equipes para ajudar as comunidades de código aberto Apache $^{5}$ (servidores) e Linux (sistema operacional).

0 acordo entre a IBM e o servidor Apache foi um divisor de águas na história do código aberto. Em 22 de junho de 1998, apenas três meses depois da reunião inicial, a IBM anunciou que daria suporte ao Apache em todos os seus produtos.

Em relação ao Linux, a empresa sabia que a adoção desse sistema operacional estava crescendo rapidamente. Os clientes perguntavam cada vez mais sobre o uso do Linux em hardware IBM, e a empresa estava descobrindo que seus novos contratados, recém-saídos das universidades, eram fluentes em Linux e apoiavam o código aberto. Portanto, em 1999, após quase um ano do início das avaliações a IBM formou um grupo de desenvolvimento de Linux.

\footnotetext{
${ }^{4}$ Linus Benedict Torvalds é o criador do sistema operacional GNU/Linux, muitas vezes chamado simplesmente de "Linux". http://pt.wikipedia.org/wiki/Linus_Torvalds. Obtido em 01/05/2008 (13:04)

${ }^{5}$ O servidor Apache (ou Servidor HTTP Apache, em inglês: Apache HTTP Server, ou simplesmente: Apache) é o mais bem sucedido servidor web livre. Foi criado em 1995 por Rob McCool, então funcionário do NCSA (National Center for Supercomputing Applications). http://pt.wikipedia.org/wiki/Servidor_Apache. Obtido em 01/05/2008 (13:57)
} 
O Linux oferecia diversas soluções, providenciais à época para a IBM, afinal, era um sistema operacional escalável que funcionaria bem em pequenos servidores e poderia sofrer acréscimos para dar conta de tarefas mais pesadas. Por ser gratuito, os clientes podiam experimentá-lo facilmente. Essas vantagens ajudariam a deslocar o lócus da diferenciação do sistema operacional para os serviços e soluções, o ponto forte da IBM.

A empresa calcula que, atualmente, economiza cerca de US\$ 1 bilhão anualmente no que lhe custaria para desenvolver um sistema operacional próprio semelhante ao Linux. 0 que ainda permitiu a IBM oferecer produtos mais baratos do que os de concorrentes como a Sun (Solaris) e a Microsoft (Windows).

A IBM desfruta da boa vontade de milhares de programadores independentes e empresariais que se empenham no crescimento da visão e da comunidade Linux. Suas capacidades de parceria e colaboração, além do seu conhecimento específico sobre como administrar relações com comunidades que não são controladas diretamente por ela mesma, mas que são ferramentas estratégicas que seus concorrentes ainda precisam dominar.

Com a IBM se posicionando anos à frente de seus concorrentes, o envolvimento da empresa com as comunidades de código aberto nos oferece o exemplo máximo de como as empresas inteligentes podem explorar redes auto-organizadas de colaboradores independentes para criar um valor inigualável.

\section{CONCLUSÕES}

Vimos que a Tecnologia de Informação e Comunicação constitui-se hoje num dos principais pilares da obtenção de vantagem competitiva nas organizações. 0 texto de Milton Friedman soube destacar com maestria a ruptura sísmica de paradigma que o advento dessa nova tecnologia tem acarretado no ambiente de negócios.

As empresas que não gerenciarem corretamente a evolução de seus sistemas de TIC estão fadadas a desaparecer do jogo de negócios da atualidade. A gestão do conhecimento e a gestão da inovação nas organizações deve passar ao topo da agenda estratégica daqueles que desejarem se manter no jogo do mercado.

\section{REFERÊNCIAS:}

ABREU, ALINE FRANÇA \& REZENDE, DENIS ALCIDES. Tecnologia da Informação Aplicada a Sistemas de Informação Empresariais. $4^{\circ}$ Edição. Editora Atlas, São Paulo, 2006.

FRIEDMAN, Thomas L.. O Mundo é Plano: Uma Breve História do Século XXI. Editora Objetiva, 2006.

LAUDON, Kenneth C.; LAUDON, Jane Price. Sistemas de Informação. Editora LTC, 1997.

NONAKA, IKUJIRO \& TAKEUCHI, HIROTAKA. Criação de Conhecimento na empresa. - Rio de Janeiro: Campus, 1997.

OLIVEIRA, Fátima Bayma. Tecnologia da Informação e da Comunicação: A Busca de uma Visão Ampla e Estruturada. Editora Pearson Prentice Hall, São Paulo, 2007.

PORTER, MICHAEL. Vantagem Competitiva: criando e sustentando um desempenho superior. - Rio de Janeiro: Elsevier, 1989. 
OLIVEIRA, Fátima Bayma. Tecnologia da Informação e da Comunicação: Desafios e Propostas Estratégicas para o Desenvolvimento nos Negócios. Editora Pearson Prentice Hall, São Paulo, 2006.

REZENDE, DENIS ALCIDES. Tecnologia da Informação Integrada à Inteligência Empresarial: Alinhamento Estratégico e Análise da Prática nas Organizações. Editora Atlas, São Paulo, 2002.

TAPSCOTT, DON \& WILLIAMS, ANTHONY D.. Wikinomics: Como a colaboração em massa pode mudar o seu negócio. Editora Nova Fronteira, 2006.

TURBAN, EFRAIM; RAINER, JR., R. KELLY; POTTER, RICHARD E.. Introdução a Sistemas de Informação. Uma Abordagem Gerencial. Editora Campus, 2007.

\section{SITES CONSULTADOS:}

http://www.inf.pucrs.br/ gilberto/microinformatica/TI.pdf (09/12/2007)

http://pt.wikipedia.org/wiki/Linus_Torvalds (01/05/2008)

http://pt.wikipedia.org/wiki/Servidor_Apache (01/05/2008)

http://pt.wikipedia.org/wiki/web_3.0. (03/06/2008) 